\title{
LA "MEGARREGIÓN ARIZONA-SONORA" COMO ZONA ESPECIFICA DE INTENSA ACUMULACIÓN (ZEIA) EN EL ESPACIO GLOBAL PARA LA EXPANSIÓN DEL CAPITAL TRANSNACIONAL DE LA FRONTERA MÉXICO-ESTADOS UNIDOS
}

\section{THE ARIZONA-SONORA MEGAREGION: A SPECIFIC ZONE OF INTENSE ACCUMULATION (SZIA) IN THE GLOBAL SPACE FOR EXPANDING TRANSNATIONAL CAPITAL AT THE US-MEXICO BORDER}

Juan Manuel Sandoval Palacios*

Introducción

En este artículo analizo cómo se ha configurado una Zona Específica de Intensa Acumulación (ZEIA) en el corredor Phoenix-Tucson (Arizona) / HermosilloGuaymas (Sonora), vía un ajuste espacial dentro del Espacio Global para la expansión del capital transnacional de la frontera México-Estados Unidos, en la cual se concentran diversos megaproyectos de infraestructura para la producción industrial de bienes de alta tecnología -en los sectores automotriz y aeroespacial-, y para procesos extractivos, principalmente de minerales metálicos como el cobre, el molibdeno, el oro y la plata; y no metálicos, como el grafito y wollastonita.

Este proceso se enmarca en el contexto de la reestructuración del capitalismo mundial por la crisis estructural del mismo en las décadas de 1970 y 1980, a instancias de la naciente Clase Capitalista Transnacional (CCT) encabezada por la fracción estadou-

\footnotetext{
* Doctor en Antropología por la University of California - UCLA - (Los Angeles/Califórnia/ EUA). Doctorante en Ciencia Política por la Universidad Nacional Autónoma - UNAM - (Cidade do México/México). E-mail: juanmanuelsan.pal@gmail.com
} 
nidense de aquélla, y que impulsó la fase actual del capitalismo mediante la dispersión y concentración del capital que globalizaron los circuitos financieros y de producción (KOLKO, 1988; ROBINSON, 2013). En esa reestructuración se reconfiguró el mapa económico de América del Norte a fines de la década de 1970 y principios de la de 1980, con la localización y/o desarrollo de complejos industriales vinculados al Complejo Industrial-Militar estadounidense para conformar lo que Markusen et al (1991) denominaron el Cinturón de las Industrias de Armamentos (Gun Belt) en el perímetro que va a lo largo de ambas costas hasta articularse con los estados que conforman la frontera sur estadounidense donde se ha impulsado la creación de un Espacio Global para la expansión del capital transnacional, que incluye el norte de México (ROBINSON, 2013; SANDOVAL, 2017a).

Este proceso fue facilitado por los mecanismos establecidos en el Tratado de Libre Comercio de América del Norte (TLCAN), principalmente el capítulo de inversión, que permitió la llegada de una gran Inversión Extranjera Directa (IED) en la región fronteriza; lo que impulsó la creación de Regiones Transfronterizas (RTF), siendo una de las primeras la Región ArizonaSonora, actualmente denominada Megarregión Arizona-Sonora. Y esta RTF es la que denomino la ZEIA "Megarregión ArizonaSonora”, misma que intento caracterizar en este trabajo.

\section{Los Espacios Globales para la expansión del capital transnacional y las Zonas \\ Específicas de Intensa Acumulación (ZEIA)}

Como resultado de la profunda crisis estructural del capitalismo mundial que se produjo durante las décadas de 1970 y
1980, los diferentes agentes que conforman este sistema (enormes empresas monopólicas industriales, comerciales y de servicios; grandes bancos; instituciones financieras como el Banco Mundial y el Fondo Monetario Internacional; gobiernos de los principales países capitalistas; y otros) impulsaron diversos mecanismos para salir de dicha crisis (KOLKO, 1988), lo que produjo una reestructuración de aquél y el consiguiente surgimiento del capitalismo global.

Sin embargo, es necesario mencionar que algunos autores (BRAUDEL, 1984; CHASEDUNN, 1990; GUNDER FRANK, 1978; TUTINO, 2005; WALLERSTEIN, 1979-1998; 2006) plantean que la globalización surgió desde el siglo XV, con el descubrimiento y conquista de América; la cual, a partir del siglo XVI, dio origen al sistema mundo. Wallerstein (2006, p.10), plantea que "Quienes proponemos el análisis de sistemas mundo (...) venimos hablando acerca de la globalización desde mucho antes de que el término fuera inventado (no, empero, como de algo nuevo sino como de algo que había sido un elemento básico para el sistemamundo moderno desde que éste comenzara en el siglo XVI)". Para este autor (p.40), el mundo en el que vivimos, el sistema-mundo moderno, tuvo sus orígenes en el siglo XVI, y estaba entonces localizado en sólo una parte del globo, principalmente en partes de Europa y de América. Posteriormente se expandió hasta abarcar todo el mundo.

Para esta perspectiva, la globalización se produjo en el ámbito de la esfera de la circulación de bienes, del comercio. De acuerdo con Tutino (2011), el mundo se volvió uno en el Siglo XVI. El crecimiento demográfico, el comercio creciente, y la recolección de impuestos pagados obligadamente en plata establecieron una gran demanda por el metal en la China de 
la dinastía Ming, justo en el momento que los españoles conquistaban territorios americanos y encontraban montañas de plata. Y menciona que, desde la década de 1550, crecientes caudales de plata del Potosí en Los Andes y de Zacatecas en el Norte de la Nueva España fluyeron hacia Europa, para ser comercializados por sedas, porcelanas y otras mercancías de China. Antes de 1600 un segundo flujo de plata zarpó anualmente de Acapulco en galeones hacia Manila para ser comercializado por mercancías chinas. La plata de las minas de las colonias americanas de un imperio europeo encontró una creciente demanda china, exacerbando el comercio global y formas comerciales que eventualmente condujeron al capitalismo.

Wallerstein (2006) menciona que es y ha sido siempre una economía-mundo (la économie-mondo de Braudel), una economía-mundo capitalista, lo que significa que es una gran zona geográfica dentro de la cual existe una división del trabajo y por lo tanto un intercambio significativo de bienes básicos o esenciales, así como un flujo de capital y trabajo; y no está limitada por una estructura política unitaria, sino que hay muchas unidades politicas tenuemente vinculadas entre sí dentro de un sistema interestatal.

Para Wallerstein (1998, p. 7), el sistema mundial capitalista se caracteriza por un proceso incesante de acumulación de capital como fuerza impulsora fundamental; y existe en él un patrón de ritmos cíclicos, los cuales se refieren a "aquello que se mide dentro de los límites espaciales y temporales de un sistema histórico determinado" (p. 254); así como tendencias seculares que encarnan las contradicciones inherentes al sistema (que corresponden a la larga $d u$ ración de Braudel). El sistema mundial es polarizado y se encuentra en un proceso de constante evolución en la organización de la producción. Existe en el sistema mundial capitalista una división axial del trabajo, en el que hay una importante tensión centroperiferia y donde prevalece un intercambio desigual entre las partes, con la existencia de áreas periféricas, semiperiféricas y centrales. Así mismo, el sistema mundial se caracteriza por la coexistencia simultánea de una economía y una sociedad global, que a su vez se encuentra dividida por medio de un sistema político interestatal. Según este autor, el centro y la periferia mantienen sus diferencias salariales geográficas gracias a dicha división política en los estados-nación, de tal manera que el costo de la fuerza de trabajo se encuentra geográficamente localizado en determinados espacios dentro del sistema mundial.

Wallerstein coincide con las ideas de Chase-Dunn (1990, p. 3, p. 38) al analizar la contradicción entre la formación simultánea de una economía mundial con un sistema político interestatal, y en su análisis de la contradicción centro-periferia como atributo del sistema mundial capitalista. Sin embargo, el segundo autor sostiene que existe un continuum de niveles intermedios entre centro y periferia, mientras que el primero se apega más hacia la triple división entre centro, semiperiferia y periferia. A su vez, este aspecto del análisis de ChaseDunn resulta más complejo, en la medida que introduce la idea que la periferalización y la diferenciación existente en el sistema mundial capitalista también puede tomar lugar dentro de los propios países centrales y periféricos.

Para la perspectiva del sistema-mundo, la coexistencia de una economía y una sociedad global, dividida a su vez por medio de un sistema político interestatal, y los procesos de acumulación, se producen en 
los ámbitos nacionales sean del centro o la periferia; sin embargo en la perspectiva teórica del llamado capitalismo global ${ }^{1}$, que es la que utilizo aquí como marco de análisis, el ámbito nacional deja de ser el centro de dicha acumulación y del sistema interestatal, pues éstos pasan a darse en el ámbito transnacional debido al proceso de reestructuración del sistema capitalista arriba mencionado, que dio impulso a una nueva fase del mismo.

Para Robinson (2013), la nueva fase de expansión del capital transnacional que avanza de manera intensiva pero también busca hacerlo de forma extensiva en el nivel global constituye cualitativamente un nuevo estadio en el desarrollo del capitalismo mundial, y está marcado por un número de cambios cualitativos en el sistema capitalista y por novedosas articulaciones de poder social: 1) el surgimiento de capital verdaderamente transnacional, y una nueva producción y un nuevo sistema financiero globales; 2) el surgimiento de una Clase Capitalista Transnacional (CCT); 3) el surgimiento de aparatos de un Estado Transnacional (ET); y, 4) nuevas relaciones de desigualdad, dominación y explotación en la sociedad global.
Para Robinson, con el hallazgo de su movilidad global, el capital ha estado reorganizando la producción en todo el mundo, de acuerdo con todo un rango de consideraciones políticas y de "costo-factor". En este proceso, los aparatos productivos nacionales se fragmentan y se integran de forma externa en nuevos circuitos globalizados de acumulación. La distinción entre una economía mundial, donde la reproducción y acumulación del capital se daba en los ámbitos espaciales del Estado-nación, y una economía global, es la globalización del proceso mismo de producción o el surgimiento de circuitos globalizados de producción y acumulación. Entonces, dice Robinson, la globalización de la producción significa la fragmentación y descentralización de complejos procesos de producción, la dispersión en todo el mundo de los diferentes segmentos de estas cadenas, y su integración funcional en vastas cadenas de producción y distribución dentro de nuevos circuitos globalizados de acumulación. Así, la globalización unifica al mundo en un solo modo de producción y un solo sistema global, provocando la integración de los diferentes países y regiones en una nueva economía global. Esto se expresa en los esquemas 1 y 2 siguientes:

1. Para la perspectiva teórica del capitalismo global, los orígenes del modo de producción capitalista también se remontan al siglo XVI. 


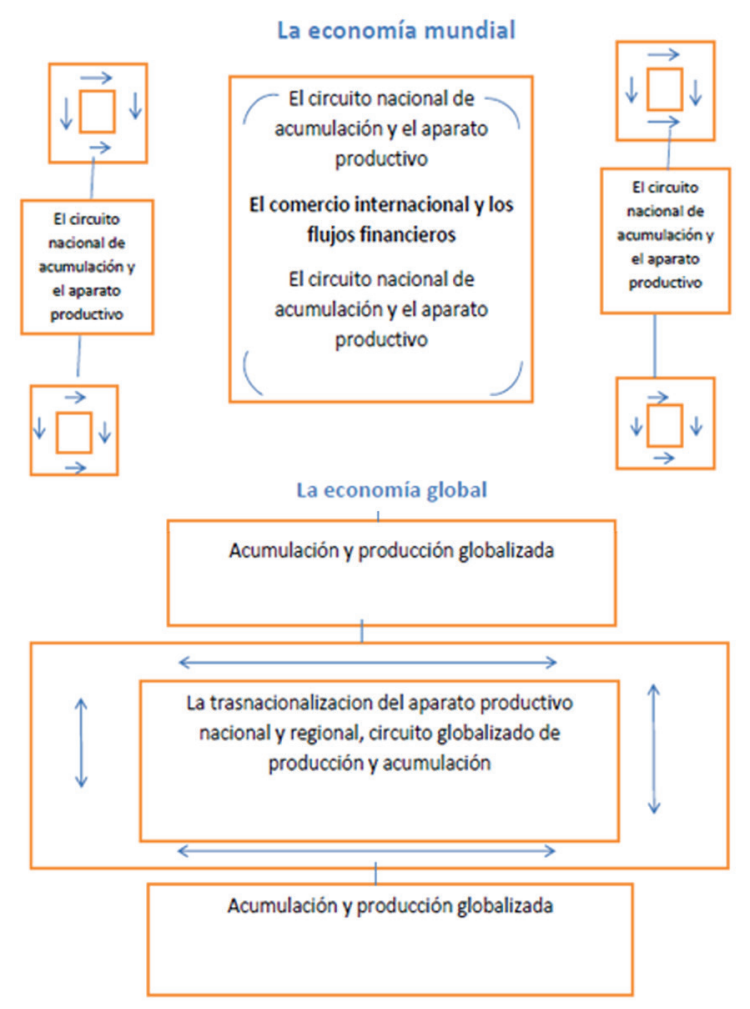

Fuente: Robinson, 2011, p. 11.

Y en esta nueva economía global, los llamados "bloques" regionales (Estado Unidos, Unión Europea y Este asiático) han formado una "triada" global cada vez más interpenetrada, basada en la interpenetración ampliada del capital entre las principales Corporaciones Transnacionales (CTN) del mundo. Robinson plantea que el análisis de los patrones globales de la inversión de las CTN indica que cada bloque fue interpenetrado por los otros dos. Y menciona que, "a medida que estos capitalistas se integran, introducen a las redes y cadenas de producción locales dentro de complejas redes transnacionales, haciendo difícil encajar las relaciones políticas entre los Estados y la competencia entre los grupos económicos en el viejo marco geopolítico del Estado-nación” (p. 172).

En esta perspectiva, Robinson dice que "dada una economía global abierta y una movilidad global del capital, un desempeño económico superior en una región particular beneficia sin duda a los grupos de inversionistas (de diversos países) en esa región" (p. 173)

Entonces, más que la competencia geopolítica entre "bloques" regionales, como algunos autores aún sostienen, Robinson apunta que los patrones regionales de acumulación reflejan ciertas distinciones espaciales, complementarias a una configuración del capitalismo global más integrado. Se trata de 
la descentralización de la economía global; su fragmentación y el surgimiento de varias zonas de intensa acumulación global. Una de tales zonas en Europa va del noroeste al sureste, por encima de las fronteras y alcanzando áreas de Europa del Este. Otra, en Norte América, es la zona fronteriza de Estados Unidos y México. Varios de estos ejes entrecruzan el Este asiático. Estos pueden no ser rivales por la hegemonía territorialmente limitada, sino sitios de acumulación intensiva en una economía global que une a capitalistas y elites transnacionales en lugares diversos en todo el mundo, precisamente lo que esperariamos de una configuración transnacional supranacional y descentralizada (p. 173).

Y en estas zonas de intensa acumulación surgen los espacios tranasnacionales o globales para la expansión del capital transnacional. Robinson (p. 126) plantea que, "En la emergente configuración global del capitalismo, el Espacio Transnacional o Global suplanta a los espacios nacionales". Esta suplantación del espacio nacional, por parte del Espacio Global, implica que el
Estado-nación en cuestión permite la subordinación de la soberanía de todo su espacio territorial, o de alguna parte de éste, a instancias transnacionales que ejercen su control sobre el emergente Espacio Global.

Considero que los Espacios Globales emergen o se producen sobre espacios que previamente han sido claves para las fases anteriores del desarrollo del capitalismo. Por sus características históricas y geográficas, ciertas zonas del planeta son claves para la intensa acumulación global, puesto que previamente han sido zonas que se han producido mediante un desarrollo geográfico desigual, producto de la diversificación, la innovación y la competencia, principalmente durante la fase anterior del capitalismo mundial para beneficiar la acumulación capitalista y por procesos de expansión geográfica del capital, como apunta Harvey (2006a). Y la frontera México-Estados Unidos, así como otras regiones del Continente Americano (el Istmo centroamericano, la Cuenca del Caribe, la Amazonía, la Cuenca de la Plata, los Andes y la Patagonia) se han desarrollado de esta forma. ${ }^{2}$

2. En el Grupo de Trabajo "Fronteras, regionalización y globalización” del Consejo Latinoamericano de Ciencias Sociales (CLACSO), del cual soy uno de los 3 coordinadores, y que está conformado por más de 200 investigadoras/es de 17 países, desarrollamos el proyecto colectivo "Espacios Globales para la expansión del capital transnacional en el Continente Americano”, donde analizamos 4 de estos Espacios Globales: Frontera México-Estados Unidos; Proyecto Mesoamérica; Amazonia; y Andino del Sur-Patagónico. 


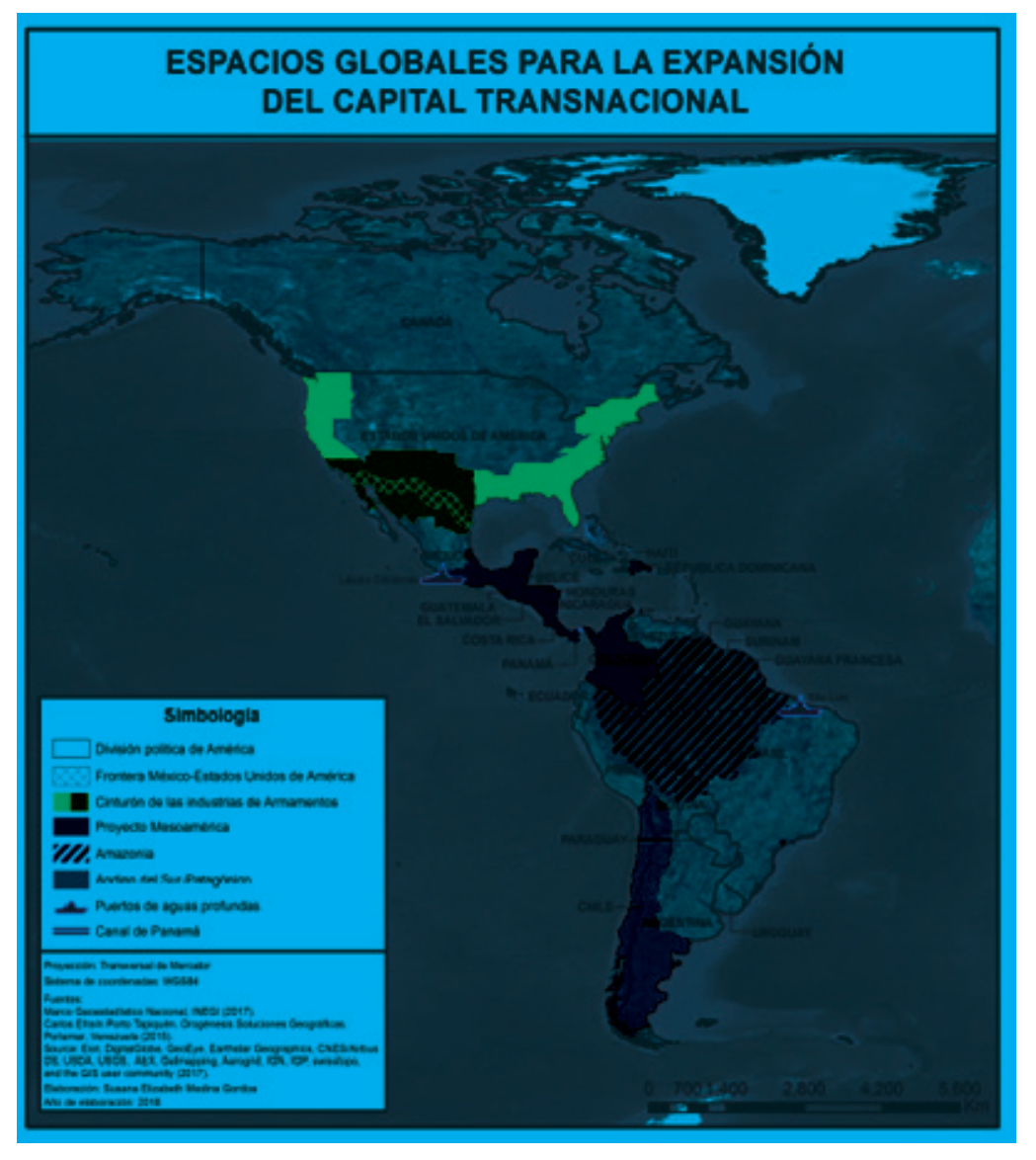

En estos Espacios Globales el capital transnacional coexiste con los capitales nacionales y locales que se reproducen en ciertos sectores, encadenados en muchas ocasiones a los transnacionales a los cuales abastecen de insumos, servicios, transporte, etcétera. Sin embargo, sólo los capitales nacionales y locales que se transnacionalizan mediante fusiones, alianzas estratégicas u otros mecanismos, son capaces de incorporarse a mayores cadenas o a clústers de corporaciones transnacionales. Los Espacios Globales se insertan al capitalismo global mediante diversos mecanismos, principalmente los establecidos en los tratados de libre comercio (inversiones, propiedad intelectual, etcétera). En el caso del
Espacio Global para la expansión del capital transnacional de la frontera México Estados Unidos, éste comenzó a emerger desde la década de 1980 pero recibió un fuerte impulso para su desarrollo y vinculación al capitalismo global a partir de la entrada en vigor del Tratado de Libre Comercio de América del Norte (TLCAN) en 1994. En otros trabajos he mostrado cómo se generó y se ha desarrollado el Espacio Global para la expansión del capital transnacional en la frontera Estados Unidos-México, cuya especificidad ha sido principalmente la de una acumulación militarizada (SANDOVAL, 2017a; 2017b; 2017c).

Dentro de los Espacios Globales para la expansión del capital transnacional, el 
movimiento y reproducción del capital es responsable de la distribución desigual en el espacio y el tiempo de la valorización del trabajo y de los bienes naturales que devienen en recursos naturales al pasar éstos, de un valor de uso a uno de cambio. Por lo tanto, en el Espacio Global se produce un proceso de desarrollo geográfico desigual y combinado, y es en este proceso que se realiza un ajuste espacial ("Spatial Fix”) (HARVEY, 2006b) en porciones del territorio para el despliegue y realización del proceso de producción industrial y/o de extracción de excedentes, de explotación de los territorios.

En síntesis, dentro de los espacios globales existen espacios menores en los cuales se concentran, vía ajustes espaciales, los megaproyectos de infraestructura para la producción industrial de alta tecnología, o para procesos extractivos, o para una combinación de ambos.

Son estas porciones de territorio, estos espacios menores, a los que denomino Zonas Especificas de Intensa Acumulación (ZEIA) (SANDOVAL, 2018). Aquí utilizo el término de Zona Específica de Intensa Acumulación (ZEIA) como una abstracción analítica, una definición operativa y un instrumento metodológico, para configurar un nivel de análisis de una totalidad concreta que se expresa en las escalas local y regional, de un proceso global.

Las Zonas Especificas de Intensa Acumulación (ZEIA), comprenden un complejo entramado de infraestructuras establecidas para la expansión del capital transnacional y para su intensa acumulación. Comprenden diversos territorios, microrregiones, localidades y zonas urbanas articuladas por medio de infraestructura de transporte y energética, donde se ha creado y desarrollado la infraestructura industrial para grandes proyectos productivos y/o extractivos, extensivos e intensivos, de corporaciones transnacionales, mismas que son apoyadas financieramente por la banca nacional e internacional y por políticas públicas de todos los niveles de gobierno, así como por acuerdos y tratados internacionales; y sus productos se valorizan en las Bolsas de Valores globales.

Estas ZEIA se superponen y expanden sobre territorios y localidades urbanas y rurales, limitando procesos de acumulación locales y afectando, en el caso de comunidades que mantienen aún el valor de uso de sus bienes naturales, su reproducción social. Pero las comunidades urbanas y/o rurales responden a ello organizándose para luchar por sus territorios; y, en el caso de comunidades y pueblos originarios, por sus territorios y sus bienes comunes.

En este trabajo me propongo analizar la ZEIA denominada "Megarregión ArizonaSonora" ubicada en el Espacio Global para la expansión del capital transnacional de la frontera Estados Unidos-México, cuya infraestructura industrial ha sido creada para la producción de bienes de alta tecnología; y para el extractivismo de minerales estratégicos (metálicos, como el cobre, el molibdeno, el oro y la plata, y no metálicos como el grafito y la wollastonita); tanto para insumos de los productos de alta tecnología, como para alimentar el sistema financiero global.

\section{La Zona Específica de Intensa Acumulación (ZEIA) de la "Megarregión Arizona-Sonora"}

El área que hoy comprende la denominada "Megarregión Arizona-Sonora" ha tenido diferentes etapas dentro del desarrollo capitalista, desde la conquista y colo- 
nización de América, principalmente en el avance de los conquistadores y colonos hacia el Septentrión novohispano. La minería, la agricultura y la ganadería fueron claves durante todo el período colonial español (casi 300 años), hasta la Guerra (18461848) donde Estados Unidos le arrebató la mitad del territorio al México independiente e impuso la actual línea fronteriza, después de haber comprado en 1853 una importante área de lo que hoy es el sur de Arizona (Tratado de Gadsten).

Es importante reflexionar aquí sobre lo que el imperio Español no pudo hacer en casi 300 años de intentos para consolidar su avance en el Septentrión Novohispano de sur a norte, durante una largo período de expansión de la acumulación originaria en estos extensos e ignotos territorios, a donde sólo era posible llegar viajando lentamente en caballo o mula, en carretas y aún caminando por el Camino Real de La Plata (Ciudad de México a Zacatecas) desde el siglo XVI, el cual fue extendido hasta Santa Fe en Nuevo México para ser denominado Camino Real de Tierra Adentro a partir del Siglo XVII, en caravanas que duraban meses en llegar desde la capital novohispana hasta Santa Fe, y a otras regiones del noroeste y del noreste durante la fase de desarrollo del Capitalismo mercantilista (que llevaba a Europa las riquezas en buques de vela y traía mercancías de la misma manera); los estadounidenses, por su parte, pudieron lograr la expansión en este mismo territorio, de Este a Oeste (del Atlántico al Pacífico,) en unos pocos años, montados en dos fases de este desarrollo capitalista, la de la acumulación originaria, mediante el despojo, y el de la acumulación ampliada del Capita- lismo industrial que avanzaba rápidamente gracias a la Revolución Industrial que se había iniciado en Europa y llegaba a este continente en buques de vapor y comenzaba a avanzar rápidamente en ferrocarril. El objetivo era el mismo, agrandar el espacio imperial y la búsqueda de oro, plata y otros minerales, además de tierras agrícolas y ganaderas, así como de rutas comerciales (SANDOVAL 2017a).

Es hasta la década de 1960 que comienza una nueva etapa de desarrollo con la instalación de las industrias maquiladoras a lo largo de la región fronteriza, pero con la crisis estructural de fines de la década de 1970 y principio de la de 1980, los agentes del sistema capitalista impulsan su reestructuración, lo que conlleva una nueva fase, la del capitalismo global (KOLKO, 1988; ROBINSON, 2013)

En ese período se comenzó a crear un nuevo Mapa Económico de Estados Unidos, con contratos para la defensa (enfocados a la Guerra Fría) en industrias de alta tecnología que se habían establecido en regiones y áreas metropolitanas, localizadas irregularmente alrededor de tres cuartas partes del perímetro estadounidense, desde el estado de Washington hasta California en la Costa Oeste, pasando por los estados desérticos del suroeste (Nuevo México y Arizona), de ahí a través de Texas y las Grandes Planicies (Great Plains), a través de Florida, y subiendo discontinuamente por la costa Este hasta New England. A esta zona perimetral algunos autores (MARKUSSEN, ET AL, 1991) la han denominado el Cinturón de las Industrias de Armamentos (Gun Belt). 
El Espacio Global para la expansión del capital transnacional en la frontera Estados Unidos-México y el Cinturón de las Industrias de Armamentos (Gun Belt)

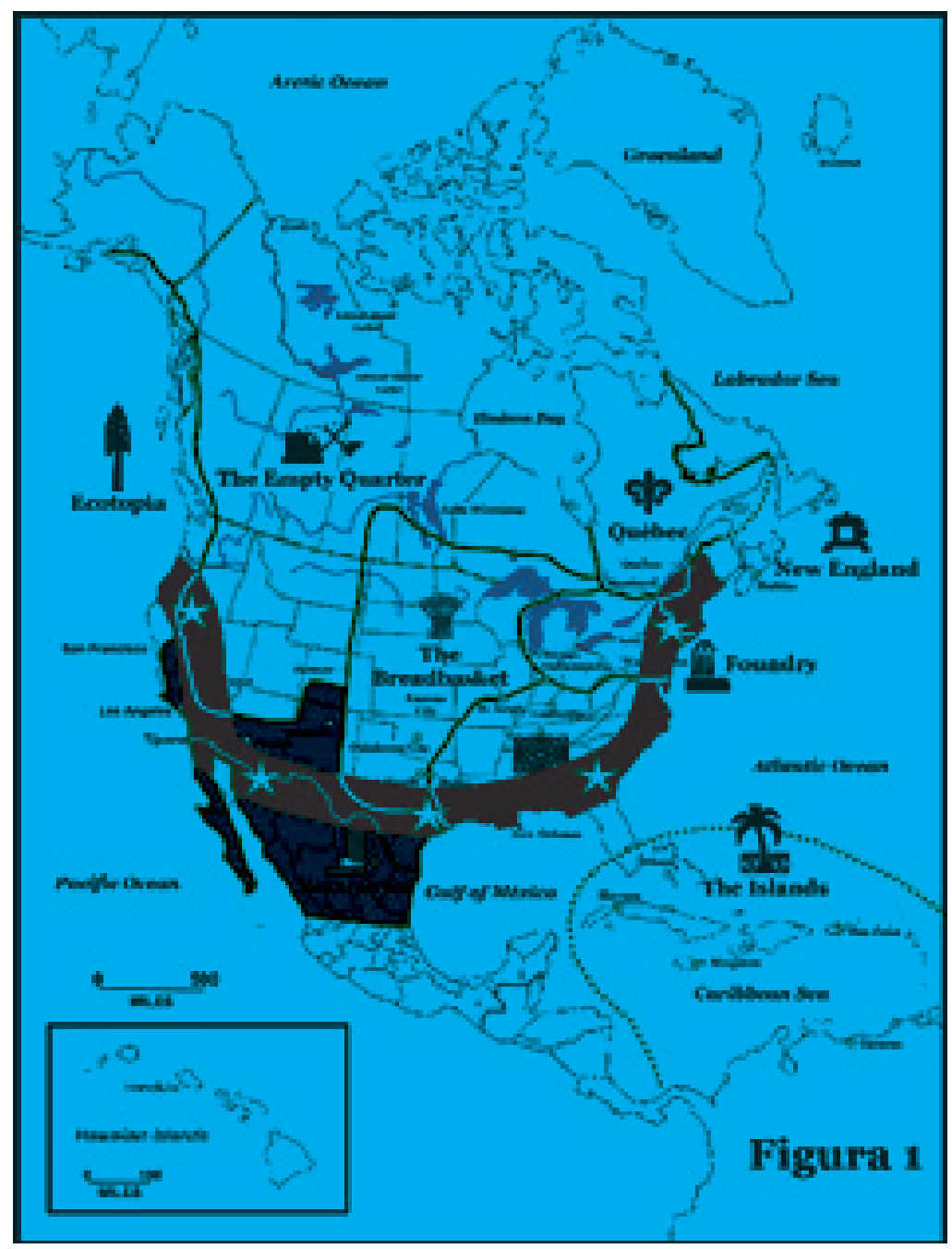

Fuentes: a) Markusen, et al (1991); b) Garreau (1982).

Mapa elaborado por Alfonso Velasco Hernández.

Al mismo tiempo Reagan impulsó la y el terrorismo. Pero la "securitización” y "securitización” y militarización de la fron- la militarización también sirvieron y ha tera sur de Estados Unidos bajo el discurso seguido haciéndolo para proteger y apode que ese país había perdido el control de yar el desarrollo del Espacio Global para la frontera y ninguna nación podía permitir la expansión del capital transnacional, en que eso pasara. Tal pérdida se debía a la el cual se comenzaron a desarrollar desde migración indocumentada, el narcotráfico principios de la década de 1990 la nueva 
Base Industrial y Tecnología de Defensa (Defense Industrial and Technology Base/ DITB)-que abarca todo el Cinturón de las industrias de Armamentos (Gun Belt)-, y un Programa para la Base Industrial de Reserva para la Defensa / Defense Reserve. Así, durante las décadas de 1990, 2000 y 2010, la "securitización” y la militarización de esta frontera se ha incrementado con el objetivo principal de controlar y proteger este Espacio Global, contribuyendo con ello a la acumulación militarizada (SANDOVAL, 2017a).

En este Espacio Global para la expansión del capital transnacional se localizan Zonas Especificas de Intensa Acumulación (ZEIA), como son la región fronteriza del sur de California (Los Angeles/San Diego) y el norte de Baja California (Tijuana/Mexicali); la región fronteriza de Tucson/Phoenix y Hermosillo/Guaymas en Arizona/Sonora; y la región fronteriza de El Paso, Texas y Ciudad Juárez, Chihuahua.

El corredor Tucson/Phoenix-Hermosillo/Guaymas, al que se adhieren otras ciudades pequeñas, fue creado como una Región Transfronteriza (Cross-Border Region/ CBR) en la década de 1990 y actualmente de se le denomina "Megarregión ArizonaSonora”. Yo la caracterizo como una Zona Especifica de Intensa Acumulación (ZEIA).

Diversos autores de los llamados Estudios Fronterizos o Transfronterizos (Border Studies o Cross-Border Studies), han planteado que el Tratado de Libre Comercio de América del Norte (TLCAN) fue el mayor impulsor de la construcción de Regiones Transfronterizas (Cross-Border Region/ CRB) a lo largo de las fronteras de Estados Unidos-Canadá y Estados Unidos-México. Pavlakovich-Kochi (2015, p. 151) plantea que el TLCAN proveyó de un marco general y la razón fundamental para las Regiones Transfronterizas (RTF) y avanzó el nivel de integración. ${ }^{3}$ Pero fue el contexto regional que contó para las diferencias a pesar del hecho de que en cada RTF se pueden identificar actores similares y sus metas correspondientes.

En el caso de los estados de Arizona y Sonora, el anuncio formal de la creación de una RTF conocida como la Región ArizonaSonora, fue hecha en 1993 unos pocos meses antes de que el TLCAN fuera puesto en marcha. Pavlakovich-Kochi plantea que

3. En un trabajo anterior (SANDOVAL, 2017a, pp. 62-63), mencioné que desde la década de 1980 la región fronteriza Estados Unidos-México había estado siendo reconfigurada como una zona de intensa acumulación global, para convertirla en un Espacio Global para la expansión del capital transnacional; y que a partir de la década de 1990 el Tratado de Libre Comercio de América del Norte (TLCAN) fue uno de los mecanismos que ayudaron a consolidar la inserción de esta región en el emergente capitalismo global. También planteé que en este Espacio Global se localizan subáreas específicas de mayor intensidad de acumulación, como son la subregión fronteriza del sur de California (Los Angeles y San Diego) y el norte de Baja California (Tijuana y Mexicali); la subregión del sur de Arizona (Phoenix y Tucson) y Sonora (Hermosillo y Guaymas); y la subregión de El Paso, Texas y Ciudad Juárez, Chihuahua, entre las principales. Y en conjunto, las subáreas a todo largo de la zona fronteriza de Estados Unidos y México configuran un patrón subregional de acumulación. Estas subáreas son las que ahora caracterizo como Zonas Específicas de Intensa Acumulación (ZEIA). 
la aparente eficiencia en la organización de una gobernanza transfronteriza y la formalización de metas específicas contribuyeron a una emergente imagen de la Región Arizona-Sonora como un modelo exitoso para el desarrollo económico transfronterizo. Un mecanismo clave del modelo formal de colaboración transfronteriza en la Región Transfronteriza Arizona-Sonora se basó en dos organizaciones apoyadas por ambos gobiernos -la Comisión Arizona-Sonora y su organización hermana la Comisión Sonora-Arizona- las cuales fueron fundadas y apoyadas por los gobiernos de cada estado desde finales de la década de 1950 (p. 151).

Pavlakovich-Kochi (p. 152) apunta que a principio de la década de 1990 los estados fronterizos vieron nuevas oportunidades de participar activamente en la facilitación de exportaciones y otras actividades transfronterizas que expandirían los mercados, crearían nuevas oportunidades de empleo y desarrollo económico benéfico para sus estados, Este nuevo enfoque impulsado por los estados para el desarrollo económico fue también una respuesta a las crecientes demandas del sector privado que solicitaba la asistencia estatal para enfrentar la creciente competencia global en general, así como la competencia con otros estados fronterizos por la posición de la "puerta” (Gateway) más favorecida dentro del área del TLCAN. Los gobiernos de los estados fronterizos han jugado un papel central en la construcción de RTF; además de los acuerdos de colaboración transfronteriza de Arizona y Sonora, se firmaron otros tratados entre los estados de California y Baja California; Nuevo México y Chihuahua, Texas y los estados del noreste mexicano de Chihuahua,
Tamaulipas, Coahuila y Nuevo León, así como entre cuatro estados fronterizos de la Unión Americana y 10 estados mexicanos. Además de los gobiernos de los estados de ambos países, los socios claves de éstos han sido los empresarios regionales, las universidades públicas y privadas y las Organizaciones No Gubernamentales.

Esta autora apunta que el estado de Arizona fue uno de los primeros estados en completar un nuevo plan estratégico para el desarrollo económico basado en los principios neoliberales. La Asociación Estratégica de Arizona para el Desarrollo Económico (The Arizona Strategic Partnership for Economic Development/ASPED, 1992) esbozó los requerimientos para una acción concentrada en apoyo de industrias y lugares con el más alto potencial para una posición competitiva globalmente, designando al sector privado para encabezar las cuestiones del desarrollo económico, e identificando la proximidad a México como la ventaja competitiva de Arizona. En esta asociación participaron activamente las oficinas para el desarrollo económico recién creadas en las universidades públicas y privadas. Entonces, con muchos miembros de la Comisión Arizona-Sonora implicados en el proceso ASPED, fue más fácil trasplantar las ideas neoliberales del modelo ASPED en un modelo regional transfronterizo para Arizona y Sonora; lo cual estaba apoyado fuertemente por una larga tradición de vínculos económicos entre los dos estados en combinación con una creciente integración transfronteriza bajo el modelo de producción compartida conocido como maquilador; y el TLCAN proveyó el marco para una utilización más eficiente de los recursos complementarios en ambos lados de la frontera. Esta combinación de circunstancias, dice la autora, acentuaron 
el modelo neoliberal transfronterizo emergente. $\mathrm{Y}$ es que la comunidad de negocios neoliberal de esta región, igual que la de otras Regiones Transfronterizas a lo largo de las fronteras norteamericanas, estaban muy interesados en redefinir las fronteras en términos del libre comercio (p.154).

La creación formal de la Región Arizona-Sonora como Región Transfronteriza (RTF), fue anunciada oficialmente en junio de 1993 en Phoenix, Arizona. En los primeros años del TLCAN se dio una expansión económica en los estados fronterizos, principalmente a través del aumento del empleo en la maquila y el comercio transfronterizo; y la construcción de la Región Transfronteriza Arizona-Sonora atrajo un número significativo de seguidores. Surgieron imágenes geográficas de corredores comerciales como la del Puerto Nuevo de Tucson (Tucson's Puerto Nuevo), que conectaba a Tucson en Arizona con el Puerto de Guaymas en Sonora; y el Corredor Canamex (Canamex Corridor) que alimentaba una visión de corredor comercial desde las provincias canadienses de Alberta y Co- lumbia Británica a la Ciudad de México, con Arizona y Sonora como el centro de actividad ("hub") (p. 155).

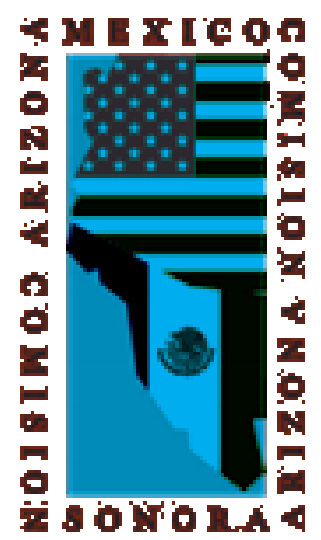

Logo de la Comisión Sonora-Arizona, muestra un mapa con los dos estados cubiertos por las banderas nacionales de ambos países.

\section{La ZEIA Megarregión Arizona-Sonora} tiene 3 componentes: Comercio, inversiones e intercambio de conocimiento. Grandes parques industriales de alta tecnología en los sectores: Aeroespacial, aviación, automotriz y minería con 1800 empresas y 140 minas. $^{4}$

\footnotetext{
4. En noviembre de 2017, el jefe de Unidad de Desarrollo Sectorial del gobierno sonorense, César Fragozo López, declaró durante la Reunión Anual de Comisiones Sonora Arizona y Arizona Mexico-Comission que la cadena de valor Sonora-Arizona ofrece a empresas, instituciones, organizaciones e individuos una plataforma competitiva para el crecimiento, combinada con una cadena de suministro sólida, una infraestructura de transporte moderna, un sistema de educación calificado y mano de obra que crea uno de los ambientes de negocios e innovación más vibrantes en cualquier parte del mundo. Abundó que dicha región ofrece ventajas importantes en sectores como: aeroespacial, agricultura, aviación, automotriz, dispositivos médicos, minería y recursos renovables, entre otros.

El intercambio comercial entre México y Arizona suma 16,700 millones de dólares, cifra que es superior al comercio de México con países como España y Reino Unido combinados. Los principales productos comerciados son agrícolas, equipos de transporte, componentes eléctricos, productos minerales, productos frescos, entre muchos otros sectores. Y mencionó que entre las ventajas competitivas que posee Sonora están: - La operación del segundo clúster aeroespacial más grande de México, el cual genera alrededor de 62,000 empleos directos.
} 


\subsection{La minería en la ZEIA "Megarregión Arizona-Sonora"}

La actividad minera en el estado de Sonora ha sido la más importante en el ámbito nacional -y ahora en el transnacional-, pues sus niveles de producción en los minerales metálicos, como el cobre y el molibdeno, y minerales no metálicos como grafito y wollastonita, lo han colocado desde 1993 en el primer lugar nacional en la minería, así como el único productor en molibdeno, grafito amorfo y wollastonita (FRANCO y VÁZQUEZ, 2014, p. 124). Pero también cuenta con importantes yacimientos de carbón, oro y plata. Este estado es donde existe la mayor cantidad de concesiones mineras de la República 5 .

\section{Centros mineros: diversidad en todas las regiones: sierra, valles y Frontera}

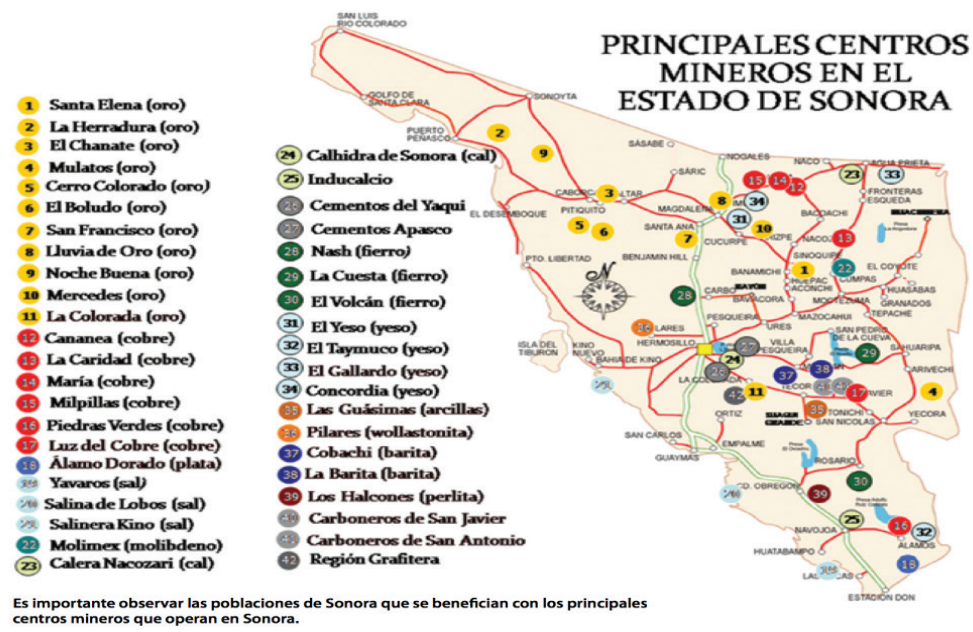

Fuente: Vázquez, 2019.

- La producción de 1,488 vehículos diarios y 98 empresas Tier 1 \&t Tier 2 con más de 50,600 empleados. - La extracción de cobre, grafito, molibdeno, oro, plata y wollastonita dentro de 140 minas. Además, es el único productor de molibdeno del país con 8,000 millones de dólares en producción minera.

Producción de 249,414 toneladas de uvas, con un valor comercial de aproximadamente 200 millones de dólares, lo que lo convierte en el primer productor de uvas de mesa en México.

Sonora tiene uno de los mayores potenciales de energía solar en México con una irradiación promedio de $6.8 \mathrm{kw} / \mathrm{h} / \mathrm{m} 2$. (PROMEXICO, 2017)

5. En 1992, el gobierno mexicano impuso modificaciones en la Constitución mexicana para el desarrollo de la Inversión Extranjera Directa (IED), con la intención de aumentar la producción minero-metalúrgica, generar empleo, desarrollar el comercio y crear riqueza para el país. A partir de 1993, con la firma y puesta en vigor del TLCAN en 1994, la producción minero-metalúrgica comenzó a crecer rápidamente, mostrando un aumento de 446.9\% de 1993 a 2012. México pasó de producir mayormente minerales no metálicos a producir minerales metálicos. (FRANCO y VÁZQUEZ, 2012, pp. 118-119). 
En Sonora existe la segunda mina de oro más grande del continente a tajo abierto (la primera está en otro estado del norte, Zacatecas). Pero el mineral más importante en Sonora, al igual que en Arizona, es y ha sido el cobre desde fines del Siglo XIX. So- nora es el mayor estado productor de este mineral en México con $84.1 \%$ de la producción total. (VÁZQUEZ, 2019). ${ }^{6}$ Y es que ambos estados forman parte del llamado Cinturón del Cobre, como se muestra en el mapa siguiente:

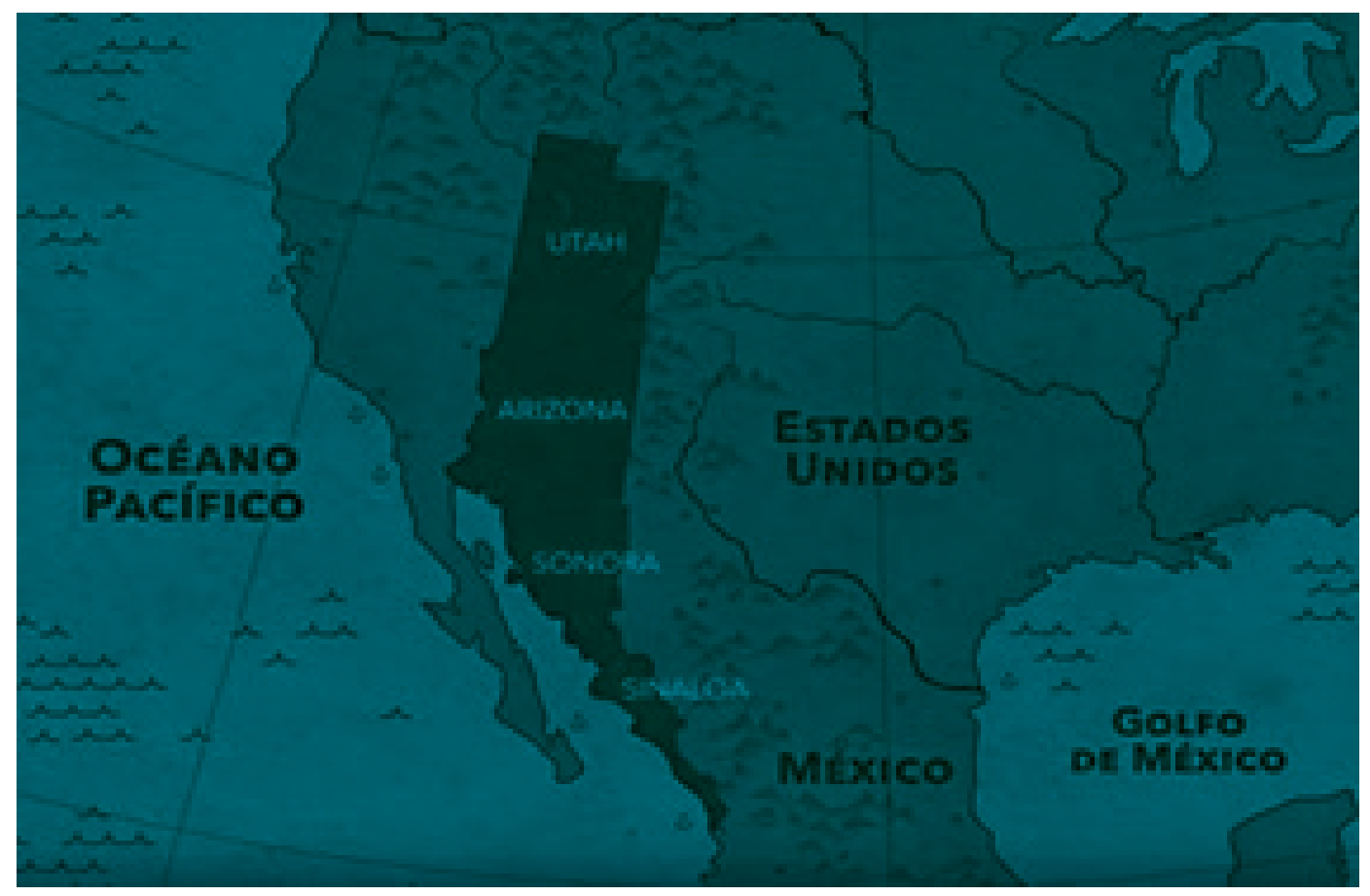

El llamado cinturón de cobre abarca desde Utah y Arizona en Estados Unidos hasta Sonora y Sinaloa en México Fuente: Flores (2018)

6. Según Taylor (2008, pp. 166-180) históricamente, la minería ha desempeñado un papel muy importante en la economía de Sonora y el noroeste de México. Los primeros reales de minas fueron establecidos en 1640. Los yacimientos descubiertos durante este periodo eran principalmente de plata Entre 1758 y 1770 se descubrieron varios yacimientos de placeres de oro en la serranía del este de Sonora, pero el más importante de los hallazgos de este tipo ocurrió en la región de Altar en 1771. En 1803 hubo nuevos hallazgos en la sierra, bonanza que duró hasta 1812 cundo la producción disminuyó debido al agotamiento de los placeres y los ataques de los apaches. Entre 1834 y 1844, de una serie de placeres de oro en la Papaguería o sección de la Pimería Alta habitada por los pápagos (el Pueblo Pápago, hoy llamado 0'odam que se encuentra tanto en el norte de Sonora como en el sur de Arizona, dividido por la línea fronteriza entre ambos países), así como al resurgimiento de algunos de los sitios más antiguos, como la Cieneguilla y San Francisco de Asís. 
Y al igual que a fines del Siglo XIX, las minas de cobre en ambos lados de la frontera pertenecen a la misma empresa. Ahora se trata del Grupo México, cuya cabeza es
Jorge Larrea, pero se trata de una corporación transnacional, con inversiones en México, Estados Unidos y Perú.

El grupo México

\begin{tabular}{|c|l|l|l|l|}
\hline $\begin{array}{l}\text { Razón } \\
\text { Social }\end{array}$ & \multicolumn{1}{|c|}{ Actividades varias } & Domicilo & $\begin{array}{l}\text { Inscripción en el } \\
\text { RPMV }\end{array}$ & $\%$ \\
\hline 1 & Grupo México, S. A. B. de C. V. & México & & \\
\hline 2 & Grupo México Servicios, S. A. de C. V. & México & & 100 \\
\hline & ACTIVIDADES DE TRANSPORTE FERROVIARIO & & & \\
\hline 3 & Infraestructura y Transportes México S. A. de C. V. & México & & 100 \\
\hline & ACTIVIDADES MINERAS & & & \\
\hline 4 & Americas Mining Corporation ("AMC") & E.E.U.U. & & 100 \\
\hline 5 & Southern Copper Corporation (SCC) & E.E.U.U. & & 84.6 \\
\hline 6 & Americas Sales Company, Inc. & E.E.U.U. & & 100 \\
\hline 7 & Minera México, S. A. de C. V. & México & & 99.95 \\
\hline 8 & Industrial Minera México, S. A. de C. V. & México & & 99.99 \\
\hline 9 & Buenavista del Cobre, S. A. de C. V. & México & & 99.99 \\
\hline 10 & Mexicana de Cobre, S. A. de C. V. & México & & 98.14 \\
\hline 11 & Southern Peru Limited & E.E.U.U. & & 100 \\
\hline 12 & Southern Peru Copper Corporation, Agencia en Chile & Chile & & 100 \\
\hline 13 & Southern Peru Copper Corporation, Sucursal del Perú & Perú & x & 99.29 \\
\hline 14 & Compañia Minera Los Tolmos, S. A. & Perú & & 97.3 \\
\hline
\end{tabular}

Fuente: Southern Copper (2014) Informe anual, p. 66. http://www.southernperu.com/ESP/relinv/2014/Annual Report//m2014esp.pdf. Consultado el 14 de septiembre, 2015.

A principio de 1850 parecía factible que ocurriera otra fiebre del oro en la región de Altar, esta vez, sin embargo, originada de afuera, por el descubrimiento de oro en California (MARSHALL and BUFFUM, 1993; Utley, 1981). Motivados por dicha fiebre del oro californiana, varios grupos de gambusinos se dirigieron a Sonora en 1851 pero fueron expulsados por las autoridades mexicanas, igual que otra expedición de estadounidenses en 1851 y de franceses en 1851-1854 (TAYLOR, pp. 180-181). El último auge minero en el noroeste de Sonora, durante el siglo XIX, ocurrió en el porfiriato. En 1880 el cobre comenzó a desplazar a los metales preciosos; pero, aun así, la producción de oro continuó desempeñando un papel relevante en las actividades mineras del estado (p. 182).

Del otro lado de la frontera, en Arizona, durante el siglo XIX los mineros se encontraron con dificultades para explorar primero por la Guerra Civil (1861-1865), en la cual el estado se puso del lado de los esclavistas, y después por la llamada Guerra contra el Pueblo Apache, que peleaba por defender su territorio. En 1877-1878 se localizaron importantes yacimientos de plata en el sur de Arizona cerca de la frontera con México. Mientras que el comercio con México se incrementó por parte de los mineros, a principios de la década de 1880 también se incrementó el interés de empresarios en invertir en la minería del lado mexicano donde ya existían dos importantes centros mineros en Nacozari y Cananea. Truett (2006), mues- 


\section{Presencia del Grupo México en Arizona y \\ Texas}

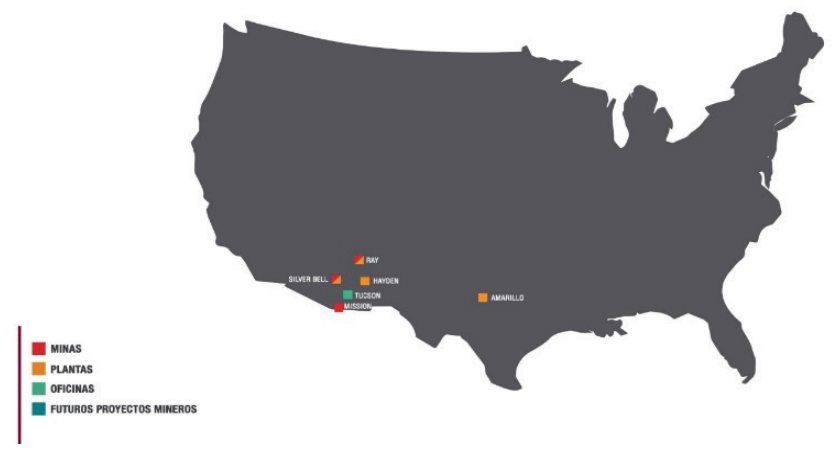

Fuente: Vázquez, 2019.

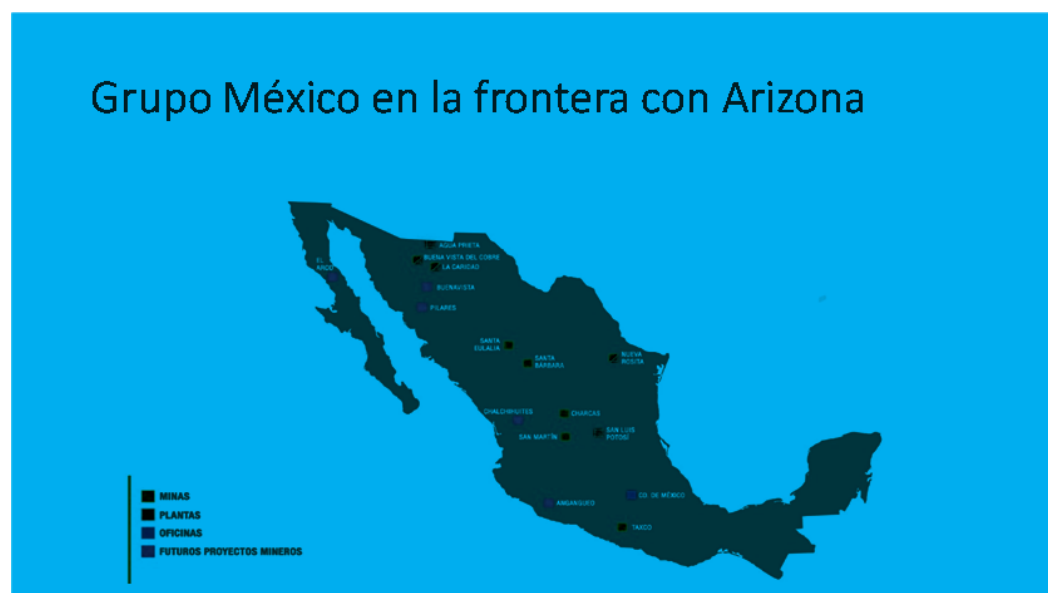

Fuente: Vázquez, 2019.

tra cómo las grandes inversiones en la minería del cobre en Sonora en la década de 1890, transformaron pueblos mineros como Nacozari con una población de pocos cientos de habitantes en ciudades de más de 20 mil, y es que el cobre se volvió un mineral estratégico para la electrificación e industrialización de Estados Unidos (y en cierta medida de México).

En 1903, miles de mineros, la mayoría de ellos mexicanos, se fueron a la huelga en Morenzi, Arizona, y fueron reprimidos por grupos de guardias privados. Varios miles de estos mismos guardias privados cruzaron armados la frontera en 1906 para reprimir la huelga de los mineros mexicanos en Nacozari, Sonora, cuya mina estaba en manos del mismo empresario de la de Morenzi (TRUETT, 2006). Desde entonces ha habido importantes movimientos y huelgas mineras, principalmente en Cananea y Nacozari. 


\subsection{La industria aeroespacial en la ZEIA "Megarregión Arizona-Sonora"}

En el sector aeroespacial México destaca por varios factores entre los países del mundo integrados a los procesos de producción global. Becerra y Vázquez (2016, p. 290), plantean que, no obstante, la relativa facilidad para mover mercancías alrededor del mundo, la vecindad geográfica con Estados Unidos es clave en términos de costos de traslado, y la alta disponibilidad de mano de obra de hombres y mujeres (en 2012 México ocupaba el primer lugar en el indice de costos de manufactura de aereopartes, 20\% menores comparados con los de Estados Unidos, de 11\% con respecto a China, y de 3\% con relación a la India) (p. 293). Todo lo anterior en el marco de apertura para la inversión extranjera directa y la liberalización comercial, contenida en el TLCAN. $^{7}$ De esta manera, apuntan los autores, México ha logrado posicionarse como uno de los principales proveedores a escala mundial, además de ser uno de los países que atrae mayor inversión extranjera directa en esta industria, debido a sus ventajas competitivas, estrategias y políticas públicas que los gobiernos federal y estatales han instrumentado para fomentar el desarrollo de este segmento de la industria manufacturera. (p. 296).

La manufactura aeroespacial en México ha registrado un importante crecimiento, con el establecimiento de empresas líderes en la fabricación de aviones y de partes que realizan operaciones de manufactura y/o ingeniería en diferentes estados de la República, en donde cada uno ha buscado una especialización. Y como consecuencia de la especialización que tiene cada uno se ha originado un agrupamiento por regiones, dividido en cinco a lo largo del territorio nacional, dos de ellos (Noroeste y Noreste) agrupando a los estados fronterizos, ubicándose a Sonora en el del Noroeste cuya especialización es la fabricación y/o ensamble de equipo eléctrico para aeronaves, partes para motor, ensamble de interiores y asientos, instrumentos de control y navegación, diseño y prueba de sistemas eléctricos (p. 304).

Estas especializaciones dan lugar a la creación de clústers del sector. El clúster de Sonora se localiza en tres ciudades: Hermosillo, Guaymas y Ciudad Obregón, cuya especialidad es la manufactura de motores y turbinas, fuselaje y materiales compuestos, para tres empresas principales: Goodrich, Esco y Roll Royce. (p. 307). ${ }^{8}$

7. También puede decirse lo mismo en el caso de Canadá, pues en Querétaro (centro-norte de México, está el principal clúster aeronáutico del país, donde la empresa de firma canadiense Bombardier tiene una planta donde se ensambla la cola del avión más grande del mundo, la cual es trasladada por carretera hasta Montreal, Canadá para armar el producto final, atravesando la frontera con Estados Unidos por Laredo, Texas y recorriendo el territorio estadounidense para cruzar la frontera con Canadá. Y el argumento para ello es el mismo: bajos costos de traslado, una de las manos de obra más barata del mundo, y las facilidades establecidas en el TLCAN.

8. En 2014 se registraron 16 empresas en el área de Nogales, Sonora, ciudad fronteriza con Nogales, Arizona. De acuerdo con Rodríguez y Lara (2014), durante los tres años anteriores se había dado una integración horizontal entre empresas que manufacturan para el sector aeroespacial; así, para 2014 se tenían 9 empresas del sector eléctrico-electrónico y cuatro en la metalmecánica junto con tres empresas 
En el caso de Arizona, éste está entre los primeros estados de la Unión Americana en la producción aeroespacial. El sector aeroespacial estadounidense es parte del llamado complejo ACE (Aeroespacial, Comunicaciones e Informática) los cuales son, junto con las industrias electrónica y la automotriz, el núcleo del Complejo Industrial Militar, y parte fundamental también del Cinturón de Industrias de Armamentos, un tercio del cual se encuentra en la frontera MéxicoEstados Unidos (SANDOVAL, 2017a).

El sector aeroespacial no sólo incluye la aviación civil y militar (aviones caza, bombardeos, drones, helicópteros), sino también satélites y misiles. Y en Tucson, la capital de Arizona, está localizada la planta de la corporación de defensa Raytheon que produce los misiles Tomahawk, una de las armas más avanzadas del arsenal militar estadounidense.

Raytheon es una corporación industrial y uno de los contratistas de defensa militares más grandes de Estados Unidos; y está compuesta de seis grandes divisiones de negocios que se encuentran distribuidos en la costa de Atlántico y en los estados fronterizos, que son parte del Cinturón de Industrias de Armamentos (Gun Belt):

- Sistemas Integrados de Defensa, basado en Tewksbury, Massachusetts.
- Sistemas de Inteligencia e Información, basado en Garland, Texas.

- Sistemas de Misiles, basado en Tucson, Arizona.

- Sistemas Centrales de Red, basado en McKinney, Texas.

- Compañía de Servicios Técnicos de Raytheon, basado en Reston, Virginia.

- Sistemas Espaciales y Aerotransportados, basado en El Segundo, California.

Los negocios de Raytheon están apoyados por múltiples operadores internacionales incluyendo: Raytheon Australia, Raytheon Canadá Limited, operaciones en Japón, Raytheon Microelectronics en España, Raytheon Systems Limited en el Reino Unido y ThalesRaytheonSystems en Francia (https://www.raytheon.com/).

Esta corporación abasteció las casi 5 docenas de los misiles Crucero Tomahawk lanzados contra una base aérea en territorio de Siria desde barcos de guerra estadounidenses en el Mar Mediterráneo el 7 de abril de 2017. El Presidente Trump ordenó el bombardeo a Siria, bajo el pretexto del uso de armas químicas por parte del gobierno de este país en contra de población civil. Unos días después, el 13 de abril, Trump ordenó el lanzamiento de la "madre de todas las bombas” (GBU-43/B, la más

del ramo aeroespacial conformando un clúster aeroespacial. Las primeras 13 ya tenían operaciones en Nogales desde la década de 1990 en la rama eléctrico-electrónica como Winchester Electronics, ITT Cannon; Amphenol Optimize Mexico, entre otras; y en el sector metalmecánico Aerocast (Sonitronies); Cr Machine (Sonitronies); Pencom CSS, entre otras más que comenzaron a funcionar hacia mediados de la década de 1990. Las tres empresas que sólo manufacturan partes y componentes específicamente para la industria aeroespacial son Magnet (Javid); Daher Aerospace y BE Aerospace (Sonitronies). Las dos primeras procesan productos metálicos aeroestructurales para aviones; y BE Aeroespace manufactura cabinas y asientos de primera clase. 
potente bomba del arsenal no nuclear estadounidense) contra un supuesto escondite del Estado Islámico en una red de túneles y grutas en territorio de Afganistán. La corporación Raytheon también está interesada en construir el muro fronterizo propuesto por Trump (El Financiero, 12 de abril de 2017; La Jornada, 12 de abril de 2017). Es importante mencionar que Trump, quien es parte de la fracción estadounidense de la Clase Capitalista Transnacional, es accionista de La corporación Raytheon.

Tras el ataque de Estados Unidos a Siria, las empresas transnacionales de defensa se posicionaron hacia arriba en la Bolsa de Wall Street. El S \& P Aerospace \& Defense Select Industry Index había alcanzado 30\% de ganancias en los primeros 3 meses de 2017 (El Economista, 10 de abril de 2017), debido a las promesas de Trump de incrementar el presupuesto militar:

- General Dynamics (tanques de combate y sistemas de vigilancia): $8.9 \%$

- Boeing (bombarderos B-52 y helicópteros Apache y Chinook): 14.88\%

- Lockheed Martin (la mayor corporación contratista, especializada en aviones de combate F-16 y helicópteros Black Hawk): 8\%

- Raytheon, que produce los misiles Crucero Tomahawk: 1.72\%.

(Ibid).

Y las acciones volvieron a subir el 22 de mayo de 2017 en la Bolsa de New York, lideradas por los sectores tecnológico y de defensa, luego que el 20 de mayo, en su primer viaje al extranjero como presidente de Estados Unidos, Donald Trump firmó un "acuerdo estratégico" con Arabia Saudita que incluía casi \$110 mil millones de dólares (109.7 mil millones) en ventas de armas estadouniden- ses. Después de que Estados Unidos y Arabia Saudita firmaron el acuerdo de provisión de armamento, en Wall Street el índice S/P del sector industrial subió 0.7\% y el S/P 500 registró su tercer día consecutivo con alzas, recuperándose de una caída sufrida la semana anterior por preocupaciones ante las perspectivas de la agenda doméstica de Trump ( $E l$ Economista, 23 de mayo de 2017, p. 4).

El acuerdo con Arabia Saudita incluía una carta de intención de "apoyar las necesidades de defensa” de ese país con la venta de una serie de buques de guerra, tanques y otros vehículos, así como servicios (RUKER y DE YOUNG, 2017) para hacer frente a grupos terroristas y proteger a Arabia Saudita de Irán, considerado por Estados Unidos la fuente principal del terrorismo. Los Saudies, por su parte, prometieron invertir miles de millones de dólares en Estados Unidos. Un vocero de la Casa Blanca dijo que este acuerdo creará una gran cantidad de empleos en la industria de defensa (DURDEN, 2017). Este es considerado el mayor acuerdo de venta de armas en la historia de Estados Unidos con el mayor comprador de armas del mundo. Pero este paquete es parte de un acuerdo de venta total de $\$ 350$ mil millones de dólares en armamento de Estados Unidos a Arabia Saudita en los próximos 10 años, y que incluye un crucial sistema de radar fabricado por la corporación Lockeed Martin (ZUESSE, 2017).

Arabia Saudita ha sido el principal comprador de armas estadounidenses y en su arsenal estaban las bombas construidas por la Corporación Raytheon en Tucson, Arizona y que fueron arrojadas en el remoto poblado de Arhab, en Yemen, por aviones sauditas respaldados por Estados Unidos en una serie de bombardeos a los poblados yemenitas el 10 de septiembre de 2016, matando al menos a 31 civiles, 3 de ellos 
niños; 42 personas resultaron heridas ( $D E-$ MOCRACY NOW, 2018).

\subsection{La industria automotriz en la ZEIA "Megarregión Arizona-Sonora"}

De acuerdo con Basurto (2016, p. 155):

El posicionamiento de México como potencia productora de vehículos ha sido registrado por algunos analistas como el elemento que justifica -a más de 20 años de la firma del TLCAN- la pertinencia desarrollista del instrumento de integración comercial, presuponiendo que el empuje del sector revela su validez al acoger el TLCAN uno de los mayores éxitos emprendidos por una industria en territorio mexicano. De este razonamiento se derivan planteamientos encaminados a utilizar el ejemplo de la industria automotriz como modelo para proyectar políticas públicas adecuadas para el desenvolvimiento de otros sectores emergentes, como el caso de la industria automotriz. ${ }^{9}$

La producción para exportación de México es de $80 \%$ del total. Este autor apunta que de la cantidad de vehículo exportados la participación de las compañías estadounidenses (Chrysler, Ford Motor y General Motors) apenas rebasa el 51\%, lo que in- dica que el espacio de producción mexicano, cuyos elementos virtuosos se asocian al TLCAN, no es aprovechado solamente por los corporativos de ese país. Las firmas de origen japonés (Honda, Nissan y Toyota) aportan 23.36\% del producto y las de origen europeo (Fiat, Volkswagen) 24.86\%. Además, en términos absolutos y relativos la producción de Volkswagen y de Nissan sobrepasa, cada una, lo que por separado aportan las tres firmas estadounidenses ( $p$. 168). Además, el registro de la inversión directa acumulada en los años recientes permite ver que la mayor proporción corresponde a las firmas europeas y japonesas, que se colocan por encima de las estadounidenses (p. 169).

La industria automotriz de México, dice Basurto (p. 169), contribuye con aproximadamente el 4\% (3.6\%) del PIB nacional, y está constituida por empresas ensambladoras que eligieron invertir en México por la cercanía al mercado estadounidense, por mano de obra barata, los bajos costos de operación y los niveles competitivos comparados con los BRICS (Brasil, India, China y Sudáfrica), pero no para cubrir el mercado nacional. En términos de distribución de las plantas automotrices por regiones en México, los centros manufactureros han desarrollado zonas fabriles en la frontera, en

9. La industria automotriz en México ha tenido un avance importante en la última década, sobre todo después de la crisis de 2008-2009, pasando del sitio número 8 de las principales naciones productoras de automóviles en 2012, al sitio número 7 en 2014 (BASURTO, 2016, p. 155). México se ubicó, por primera vez en la historia, en el sexto lugar de la producción mundial de vehículos en 2018, de acuerdo con el reporte de la Organización Internacional de Fabricantes de Vehículos Motorizados (OICA, por sus siglas en inglés). En Latinoamérica, México conserva el primer lugar en fabricación de unidades automotoras, su competidor más cercano es Brasil, que ocupa el octavo lugar de la producción mundial (EXPANSIÓN, 2019). 
el Bajío y en el centro del país, siendo las de la frontera (Ford, GM y Chrysler) las que recibieron grandes inversiones en la década de 1990; las más recientes de Volkswagen y Nissan lo hacen en Aguascalientes, Puebla y Guanajuato; y aún los más recientes en Puebla (Audi), Salamanca, Guanajuato (Honda), Silao, Guanajuato (motores Volkswagen) y Aguascalientes (Mercedes Benz) (p. 170).

Estas plantas van acompañadas de industrias de suministro de partes, que configuran clústers regionales. En el caso del corporativo de Ford Motor se señala el despliegue del clúster automotriz de Sonora, con un parque proveedor con 42 empresas de T1 y T2, y la planta de estampado y ensamble de Hermosillo, que produce $44 \mathrm{mil}$ vehículos al año y genera entre 15 y 20 mil empleos (p. 171) ${ }^{10}$.

Y en el caso de Arizona, ahí se va a construir en la planta más avanzada del mundo en autos eléctricos. La construcción de la planta automotriz Lucid Motors Company, con una inversión de casi 700 millones de dólares en Casa Grande, a unos 75 $\mathrm{km}$ al sureste de Phoenix, tendrá asociación con proveedoras de Sonora.

Lucid Motors (anteriormente Atieva) es una compañía desarrolladora de vehículos eléctricos fundada en 2007 y basada en Men- lo Park, California. El 29 de noviembre de 2016 se anunció la construcción de la primera fábrica de la firma por un valor de $\$ 675$ millones en Casa Grande, Arizona. Se calcula que empleará hasta 2,000 trabajadores en 2022, y pudiendo construir 20,000 a 130,000 coches al año. Inicialmente Lucid desarrolló baterías, pero en 2014 creó un prototipo de coche eléctrico de aluminio. Originalmente llamado "Atieva Atvus" fue presentado como el "Lucid Air" en diciembre de 2016 y disponible aproximadamente 2 años más tarde. La empresa automotriz consiguió en septiembre de 2019 un respaldo de mil millones de dólares del Fondo de Inversiones Público de Arabia Saudita para ocupar un lugar privilegiado en el mercado de vehículos eléctricos (AUTOBLOG, 2019; RINGLE, 2019).

\subsection{Las universidades y las Organizaciones No Gubernamentales (ONG) en la ZEIA "Megarregión Arizona-Sonora"}

En el caso de intercambio de conocimiento, Miller (2014: 51-52) muestra el papel de los contratistas, investigadores universitarios y el Departamento de Seguridad de la Patria (DHS) en este estado. La Universidad de Arizona se ha vuelto un laboratorio para el Departamento de Seguridad de la Patria (DHS). Es parte del Centro

10. Sonora tiene la planta de Ford Motor de estampado y ensamble más moderna del mundo, la cual actualmente está siendo ampliada al doble para trasladar a México la producción de la van Transit Connect de próxima generación desde España a partir de 2020. La decisión del fabricante estadounidense de construir su Transit Connect de próxima generación en México, después de años de importarla desde España, es obtener más piezas para la camioneta desde ubicaciones de América del Norte para cumplir con los requisitos del nuevo acuerdo comercial entre México, Estados Unidos y Canadá, T-MEC, que espera ser ratificado en el congreso de los tres países. La planta de Hermosillo también podría ser la nueva casa de la cuarta generación del Ford Escape, que está perdiendo terreno en Estados Unidos frente a sus competidores como el Chevrolet Equinox de manufactura mexicana (RODRÍGUEZ, 2019). 
para la Seguridad Fronteriza y de Inmigración del DHS, conocido como BORDERS. En 2008, la Universidad recibió una subvención por \$ US 17 millones de dólares, para desarrollar investigación sobre seguridad fronteriza durante 6 años. BORDERS lidera un consorcio de 14 "instituciones de primer orden (premier)" consistente no solo de universidades abarcando todo el país, sino también la Corporación RAND ubicada en Santa Mónica, California, y el Migration Policy Institute, un centro de análisis (Think Thank) ubicado en Washington, D. C. La Universidad de Arizona también tiene un Parque Tecnológico (Tech Park). Muchas compañias presentes en el parque trabajan en tecnologías de la frontera, tales como DILAS, Pillar Innovation, Raytheon, IBM, Oracle, Cannon, NO Photonics, y DRS Technologies. Este autor dice que las líneas entre académicos, la industria privada, $\mathrm{y}$ el control de la frontera están volviéndose borrosas de manera creciente.

Recientemente, en 2018, un grupo llamado MEXICANS AND AMERICANS THINKING TOGETHERMATT, que es un organismo binacional cuya misión es la de construir puentes de entendimiento entre México y Estados Unidos para contribuir a mejorar la calidad de vida de sus habitantes, y que cuenta con un Consejo compuesto por líderes empresariales, religiosos, políticos, filántropos y de educación superior, promovió, en el marco de las negociaciones del nuevo tratado de libre comercio, un estudio denominado Economía Fronteriza Estados Unidos-México (US-Mexico Bordernomics) para mostrar las relaciones comerciales actuales entre todos los estados fronterizos (MEXICANS AND AMERICANS THINKING TOGETHERMATT, 2018).

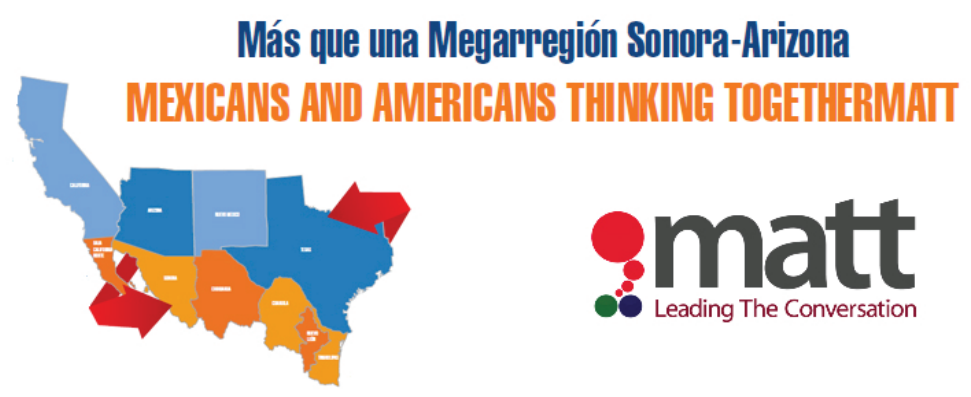

Fuente: Mexicans and Americans Thinking Togethermatt, 2018.

Con dicho estudio MATT busca proporcionar un mejor entendimiento de las oportunidades económicas existentes en esta importante región. De acuerdo con MATT, el estudio ayudará a incrementar el reconocimiento que brinda esta posición geográfica estratégica, centrada en una megarregión económica, que provea a ambos países una ventaja competitiva en el mercado global, generando empleos y oportunidades.
Además, el estudio se enfoca en el comercio fronterizo y el flujo laboral, tanto a nivel regional como económico.

En el estudio de Bordernomics se calcula que la actividad anual de negocios en los cuatro estados fronterizos de Estados Unidos y los 6 estados fronterizos de México, es de 9.1 millones de millones de gastos mientras que el potencial total de exportaciones para el área de los 10 estados se 
calcula en casi 2.3 millones de millones por año (PERRYMAN, 2018).

En septiembre de 2018, y a partir de este estudio, líderes de negocios de ambos lados de la frontera formaron la Alianza de la Economía Fronteriza (Bordernomics Alliance) con el objetivo de impulsar la ventaja económica competitiva de la región fronteriza Estados Unidos-México, proveyendo a sus miembros una ventaja competitiva al utilizar los datos obtenidos en el estudio enfocado en estrategias financieras modernizadas para la inversión que produzca resultados positivos. La alianza está compuesta por 20 empresas mexicanas y 20 empresas americanas, que representan a las industrias más importantes de esta importante región. Y la Misión de la misma es: Incrementar la prosperidad económica y la calidad de vida de los estados fronterizos de Estados Unidos y México colaborando en los siguientes rubros: Defensa legal, Comercio, Redes (Networking), e Intercambio de Información (CHAPA, 2018).

Los sectores involucrados en este plan de desarrollo regional son los de: Energía, Automotriz Manufactura, Agricultura, Salud, Transporte, Maquiladora, Finanzas, Hospitalidad, Ventas al Menudeo, Tecnología, Comunicación, Centros de Datos, Agencias Aduanales y otros sectores relevantes para los estados participantes, México, Nuevo León, Baja California, Chihuahua, Tamaulipas, Coahuila y Sonora y, por EE.UU., Cali- fornia, Arizona, Nuevo México, Texas.

El vicepresidente y funcionario corporativo de negocios estratégicos de la corporación Sundt Construction Inc., en San Antonio, Texas, John Carlson, fue electo presidente del consejo de dicha alianza; los vicepresidentes electos son Ryan Richardson, jefe de AHMSA International, el productor de acero más grande de México, y Tracye McDaniel, fundador de $\mathrm{McDa}-$ niel Strateg Ecosystems y anterior CEO del Texas Economic Development Group. Los miembros fundadores de la alianza incluyen empresarios de Altos Hornos de México, Genie Holdings, Greater Brownsville Incentives Corp., International Bank of Comerce, Texas Asociation of Business; MATT Foundation Inc., Mission Economic Development Corp., Sundt Construction y Texas Association of Dairyme (CHAPA, 2018).

Es decir, lo que la Alianza de Economía Fronteriza (Bordernomics Alliance) busca impulsar, siguiendo el modelo de la "Megarregión Arizona-Sonora", es que se incorpore a todos los estados fronterizos de ambos países en una sola Megarregión ${ }^{11}$. Lo que significa darle un nuevo impulso al desarrollo del Espacio Global para la expansión del capital transnacional de la frontera Estados Unidos-México, mediante el reforzamiento de la infraestructura y las inversiones en las Zonas Especificas de Intensa Acumulación (ZEIA), a partir del modelo de la "Megarregión Arizona-Sono-

11. Vázquez y Bocanegra (2013, pp. 243-260) han denominado a esta gran región, como región intermedia o región transfronteriza intermedia, cuya integración es multidimensional (económica, social y cultural), pero en el ámbito de la integración económica ésta se ha venido dando mediante corredores económicos (urbanos; industriales-manufactureros; comerciales; inmobiliarios; del conocimiento). 
ra”, el cual es seguido muy de cerca por la "Región California-Baja California”. ¿0 es al revés?. En otro estudio sobre la Región California-Baja California intentaremos mostrar cuál es el estado de desarrollo de esta región.

\section{Conclusiones}

En ese trabajo he utilizado la perspectiva teórica del capitalismo global desarrollada por William I. Robinson, para mostrar cómo se ha venido creando y desarrollando el Espacio Global para la expansión del capital transnacional de la frontera Estados Unidos-México, cuya especificidad es la acumulación militarizada, como lo analizo en otro trabajo (SANDOVAL, 2017a). Asimismo, muestro que dentro de este Espacio Global se han dado ajustes espaciales, en el contexto planteado por Harvey del desarrollo geográfico desigual, para crear lo que he denominado como Zonas Específicas de Intensa Acumulación (ZEIA), a partir del establecimiento por parte de elites políticas, económicas y sociales de ambos lados de la frontera, de lo que han denominado Regiones Transfronterizas (RTF). Analizo la llamada Región Arizona-Sonora, que fue la primera que fue establecida en 1993, en el marco de la firma del TLCAN; y cuya especificidad está basada principalmente en el desarrollo económico de sectores productivos industriales de alta tecnología (automotriz y aereoespacial), y en el sector extractivo de la minería de gran escala, siendo este último sector en esta región el que históricamente ha sido de gran importancia para el desarrollo del capitalismo en México y Estados Unidos desde fines del Siglo XIX. A partir de este análisis, caracterizo a esta RTF como una ZEIA, de acuerdo a la definición operativa que establezco en el texto.
Los mecanismos que las Comisiones Arizona-Sonora y Sonora-Arizona han venido impulsando después de la crisis de 2008 y 2009, junto con representantes de sectores empresariales, académicos, sociales y políticos de ambos estados, aliadas con corporaciones transnacionales, para darle un nuevo impulso a la RTF denominándola "Megarregión Arizona-Sonora”, es la expresión, en el nivel local/regional de lo que la CCT ha venido impulsando en diversas partes del mundo, principalmente en los Espacios Globales para la expansión del capital transnacional, para intentar salir de la crisis económica recuperando los niveles de acumulación en el ámbito transnacional de antes de la crisis e ir aún más allá, atrayendo más IED para ello.

En el caso de la "Megarregión ArizonaSonora", la especificidad de ésta se basa como ya lo mencioné, en sectores productivos industriales de alta tecnología, y en el sector extractivo de la minería de gran escala. Las especificidades de las otras RTF o ZEIA varían en función del contexto histórico y de los sectores económicos que han prevalecido en ellas; sin embargo, en conjunto las ZEIA que configuran el Espacio Global para la expansión del capital trasnacional de la frontera Estados UnidosMéxico, forman asimismo un patrón subregional de acumulación, puesto que son complementarios entre sí y, en conjunto, con otros espacios globales.

Por supuesto que estos megaproyectos industriales de producción de bienes de alta tecnología y de extractivismo minero de gran escala tienen impactos socioambientales en los trabajadores y las comunidades, mismas que responden de manera organizada o no, a los impactos de los mismos (exigencia de mayores salarios y de mejores condiciones laborales y de vida, lu- 
chas y demandas contra la contaminación de maquiladoras y la producción minera, defensa de territorios y bienes comunes, etcétera). Pero estas cuestiones requieren necesariamente de un profundo análisis, el cual, por otro lado, me encuentro elaborando conjuntamente con otros miembros del Grupo de Trabajo "Fronteras, regionalización y globalización en América” del Consejo Latinoamericano de Ciencias Sociales (CLACSO), dentro del proyecto colectivo sobre "Espacios globales para la expansión del capital transnacional en el Continente Americano"

\section{Referencias}

AUTOBLOG. Lucid Motors begins dozer work for $\$ 675$ million Arizona Factory. October 2, 2019. Retrieved from: https://www.autoblog. com/2019/10/02/lucid-motors-ev-arizona-factoryl

BASURTO, R. La relevancia de la industria automotriz en la definición del regionalismo norteamericano. En, BOCANEGRA, C. y VÁZQUEZ, M. A. (Coords). Integración económica. Dinámica y resultados. México: Jorale Editores y Universidad de Sonora, 2016, pp. 155-179.

BECERRA, A. M. y VÁZQUEZ, M. A. La industria aeroespacial en México: Situación y perspectivas. En, BOCANEGRA, C. y VÁZQUEZ, M. A. (Coords). Integración económica. Dinámica y resultados. México: Jorale Editores y Universidad de Sonora, 2016, pp. 289-309.

BRAUDEL, F. Civilización material, economía y capitalismo. Siglos XV-XVIII. Madrid: Alianza, 1984.

CHAPA, S. Sundt executive to chair new cross-border trade group. San Antonio Business Journal, September 20, 2018. Retrieved from: https://www.bizjournals.com/sanantonio/ news/2018/09/20/sundt-executive-to-chair-newcross-border-trade.html
CHASE-DUNN, CH. Global Formation-Structures of the World Economy. Cambridge: Blackwell, 1990.

DEMOCRACYNOW. De Arizona a Yemen: cómo las bombas construidas por Raytheon en Tucson mataron a 31 civiles en un poblado yemení. 17 de diciembre, 2018. Recuperado de:

https://www.democracynow.org/ es/2018/12/17from arizona to yemen how bombs

DURDEN, T. Trump Signs Single Largest Arms Deal in US History with Saudi Arabia Worth \$350 Billion. Global Research, May 22, 2017. Retrieved from: http://www.globalresearch.ca/trump-signssingle-largest-arms-deal-in-us-history-withaudi-arabiaworth50illion/5591313?utm_ campaign=magnetEtutm_source=article_ pagectutm_medium=related_articles

EL ECONOMISTA. "Tras ataque de EU a Siria las empresas de defensa se posicionan en Bolsa", 10 de abril, 2017.

EL ECONOMISTA. "Gira de Trump impulsa a Wall Street." (Termómetro Económico) 23 de mayo, 2017, p. 4.

EXPANSIÓN. México sube al sexto lugar mundial en producción de vehículos. 7 de abril, 2019. Recuperado de: https://expansion.mx/empresas/2019/04/17/mexicoocupa-el-sexto-lugar-en-produccion-de-vehiculos

EL FINANCIERO. Bombardeo a Siria dio beneficios a Trump. Raytheon, donde tiene acciones, surtió misiles. 12 de abril, 2017.

FLORES, 0. Mina La Caridad, un emblema de la minería mexicana. Conoce su historia. Minería en Línea, 14 de octubre, 2018. Recuperado de: https://mineriaenlinea. com/2018/02/mina-la-caridad-emblema-la-mineriamexicana-conoce-historia/

FRANCO, E. M. y VÁZQUEZ, M. A. Marco teórico y conceptual para el estudio de la integración minera sonorense mediante la recepción de inversión extranjera directa. Tendencias Económicas, Año 5, Volumen 10, Juliodiciembre, pp. 111-130, 2014.

GARREAU, J. The Nine Nations of North America. New 
York: Avon Books, 1981.

GUNDER FRANK, A. World Accumulation, 1492-1789. New York Monthly Review, 1978.

HARVEY, D. Limits to Capital. London and New York: Verso, 2006.

HARVEY, D. Spaces of global capitalism.

Towards a Theory of Uneven Geographical Development. London and New York: Verso, 2006.

KOLKO, J. Restructuring the World Economy New York: Pantheon Books, 1988.

LA JORNADA, 12 de abril de 2017.

MARKUSEN, A.; HALL, P.; CAMPBELL, S.; and DEITRICK, S. The Rise of the GunBelt. The Military Remapping of Industrial America. New York: Oxford University Press, 1991.

MARSHALL, J. W. and BUFFUM, E. G. From

Mexican Days to the Gold Rush. Memoirs of James Wilson Marshall and Edward Gould Buffum Who Grew Up with California. Edited by Dennis B. Nunis, Jr. Chicago: The Lakeside Press, R.R. Donnelley and Sons Company, 1993.

MEXICANS AND AMERICANS THINKING TOGETHERMATT. MÁS QUE UNA MEGARREGIÓN SONORA - ARIZONA. ElConstructor10, 2018. Retrieved from: http://elconstructor10.mx/masque-una-megarregion-sonora-arizona/

MILLER, T. Border Patrol Nation: Dispatches from the Front Lines of Homeland Security. San Francisco: City Light Books, 2014.

PAVLAKOVICH-KOCHI, V. Re-Building CBRs in 21st Century: Lessons from the Arizona-Sonora Region. In, BARAJAS, M. R., WONG-GONZÁLEZ, P. y ODDONE, N. (Coords). Fronteras y procesos de integración regional. Estudios comparados entre América y Europa. México: El Colegio de la Frontera Norte, Centro de Investigación en Alimentación y Desarrollo, Juan Pablo Editor, 2015, pp. 151-167.

PERRYMAN, R. Bordernomics Defining Economic Opportunities, Potential, and Challenges Confronting the US - Mexico Border Region and
Strategies for Enhanced Prosperity. Highlights of Study Findings and Results. An Analysis by The Perryman Group for MATT: Mexicans and Americans Thinking Together, 2018.

PROMEXICO. Sonora y Arizona impulsan la inversión en la megarregión. Reunión Anual de Comisiones Arizona-Sonora. 01 de diciembre, 2017. Recuperado de: https://www.gob.mx/ promexico/articulos/sonora-y-arizona-impulsanla-inversion-en-la-megarregion

RINGLE, H. Lucid Motors gets site plan approval, begins hiring for Arizona plant. PHOENIX BUSINESS JOURNAL, Oct. 10, 2019. Recuperado de: https://www.bizjournals.com/phoenix/ news/2019/10/10/lucid-motors-gets-site-planapproval-begins-hiring.html

ROBINSON, W. I. Conflictos transnacionales: Centroamérica, cambio social y globalización. San Salvador: UCA Editores, 2011.

Una teoría sobre el capitalismo global. Producción, clase y estado en un mundo transnacional. México: Siglo XXI, 2013.

RODRÍGUEZ, I. Ford despide producción de autos para ensamblar camionetas en México. AUTOMOTIVE NEWS MEXICO, abril 01, 2019. Recuperado de: https://mexico.autonews.com/plantas-y-produccion/ford-despide-produccion-de-autos-paraensamblar-camionetas-en-mexico

RODRÍGUEZ, J. G. y LARA, B. Empresas trasnacionales en la industria aeronáutica en Nogales, Sonora, ¿especialización transfronteriza vía cadenas globales de valor o maquila clásica? En, RODRÍGUEZ, A. B. y CONTRERAS, 0. F. (Coords). Memorias del $4^{\circ}$ Congreso Nacional de Ciencias Sociales. Tijuana, B. C., Chiapas: Centro de Estudios Superiores de México y Centroamérica de la Universidad de Ciencias y Artes de Chiapas, y COMECSO (El Colegio de la Frontera Norte), 2014 , pp. 3-16.

RUKER, P. y DEYOUNG, K. Armas, Irán y el EI, el menú de Trump. En Arabia Saudita el presidente de EU explota su perfil de businessman. El Economista, sección: selección del Washington Post, 
22 de mayo, 2017, p. 49.

SANDOVAL, J. M. La frontera Estados Unidos

- México: espacio global para la expansión del capital transnacional. México: Instituto Nacional de Antropología e Historia, 2017a.

La frontera Estados Uni-

dos-México como espacio global o transnacional. En, PADILLA, H., FURLONG, A., NETZAHUALCOYOTZI, R. Y SANDOVAL, J. M. (Coords.) Las fronteras: espacios estratégicos para la globalización. Universidad Autónoma de Ciudad Juárez y Benemérita Universidad Autónoma de Puebla, 2017b, pp. 45-104.

US-Mexico border states

and the US military-industrial complex. A Global Space for expanding transnational capital. Regions and Cohesion, Regiones y Cohesión / Regions et Cohesion (Berghahn Journals: New York and Oxford), Volume 7, Issue 1, Spring (March 1), pp. 87-121, 2017c.

El eje minero-energético del Istmo de Tehuantepec como Zona Específica de Intensa Acumulación (ZEIA) en el Espacio global del Proyecto Mesoamérica para la expansión del capital transnacional. Trabajo presentado en el Taller de Análisis y Discusión "El desarrollo de megaproyectos mineros en las Zonas Específicas de Intensa Acumulación (ZEIA) de los Espacios Globales para la expansión del capital transnacional en el Continente Americano." Sala de Juntas del Departamento de Economía, Universidad de Sonora, Hermosillo, 21 de agosto de 2019.

Taylor, L. La riqueza escondida en el desierto: la búsqueda de metales preciosos en el noroeste de Sonora durante los siglos XVIII y XIX. Región y Sociedad, Vol. XX, No. 42, pp. 165-190, 2008.

TRUETT, S. Fugitive Landscapes. The Forgotten History of the U. S. -Mexico Borderlands. New Haven and London: Yale University Press, 2006.

TUTINO, J. Making a New World. Founding Capitalism in the Bajio and Spanish North America. Durham and London: Duke University Press,
2011.

UTLEY, R. M. Frontiersmen in Blue. The United States Army and the Indian, 1848-1865. Lincoln and London: University of Nebraska Press, 1967 (1981, First Bison Book Printing).

Frontier Regulars: The United

States Army and the Indian, 1866-1891. Lincoln and London: University of Nebraska Press, 1973.

VÁZQUEZ, M. A. La minería de gran escala en la ZEIA de la Megarregión Sonora-Arizona en el Espacio Global de la frontera México-EstadosUnidos. Trabajo presentado en el Taller de Análisis y Discusión "El desarrollo de megaproyectos mineros en las Zonas Específicas de Intensa Acumulación (ZEIA) de los Espacios Globales para la expansión del capital transnacional en el Continente Americano." Sala de Juntas del Departamento de Economía, Universidad de Sonora, Hermosillo, 21 de agosto 2019.

y BOCANEGRA, C. La región transfronteriza Méx/EUA: algunas formas de integración. In: BOCANEGRA, C. y VÁZQUEZ, M. A. (Coords.). Procesos de integración económica regional. México: Universidad de Sonora y Pearson Educación de México, S.A de C.V. 2013, pp. 243-260.

WALLERSTEIN, I. El moderno sistema mundial, 3 volúmenes. México: Siglo XXI, 1979-1998. El capitalismo histórico.

México: Siglo XXI, 1998.

Análisis de Sistemas-Mundo. Una introducción. México: Siglo XXI, 2006, 2a Edición.

ZUESSE, E. U.S. \$350 Billion Arms-Sale to Sauds Cements U.S.-Jihadist Alliance. Global Research, May 22, 2017. Recuperado de: http://www.globalresearch.ca/u-s-350-billion-arms-sale-to-saudscements-u-s-jihadist-alliance/5591350 


\section{RESUMEN}

En este artículo analizo cómo se ha configurado una Zona Específica de Intensa Acumulación (ZEIA) en el corredor Phoenix-Tucson (Arizona) / HermosilloGuaymas (Sonora), vía un ajuste espacial dentro del Espacio Global para la expansión del capital transnacional de la frontera México-Estados Unidos, en la cual se concentran diversos megaproyectos de infraestructura para la producción industrial de bienes de alta tecnología -en los sectores automotriz y aeroespacial-, y para procesos extractivos, principalmente de minerales metálicos como el cobre, el molibdeno, el oro y la plata; y no metálicos, como el grafito y wollastonita. Este proceso se enmarca en el contexto de la reestructuración del capitalismo mundial por la crisis estructural del mismo en las décadas de 1970 y 1980, a instancias de la naciente Clase Capitalista Transnacional (CCT) encabezada por la fracción estadounidense de aquélla, y que impulsó la fase actual del capitalismo mediante la dispersión y concentración del capital que globalizaron los circuitos financieros y de producción, dando paso a la creación de Espacios Globales para la expansión del capital transnacional en diversas partes del mundo y, dentro de éstas, la producción de Zonas Específicas de Intensa Acumulación.

\section{PALABRAS CLAVE}

Capitalismo global. Expansión. Acumulación. Transnacional. Megaproyectos. Infraestructura.

\section{ABSTRACT}

In this paper I analyze how a Specific Zone of Intense Accumulation (SZIA) has been created in the Phoenix-Tucson (Arizona) / Hermosillo-Guaymas (Sonora) corridor throughout a spatial fix within the Global Space for Expanding Transnational Capital at the US-Mexico Border. Diverse infrastructure megaprojects for industrial production of high technology goods -in the auto and aerospatial sectors- are concentrated in this SZIA; but also megaprojects for extractive processes, mainly of metallic minerals as copper, molibdem, gold and silver, and non metallic ones such as grafitt and wollastonit. This process is analyzed in the context of the restructuring of world capitalism in the 1970s and 1980s, promoted by the emergent Transnational Capitalist Class led by the US fraction of this Class. This restructuration encouraged global capitalism by dispersing and concentrating capital throughout the globalization of financial and production circuits which produced Global Spaces for expanding transnational capital in diverse regions of the world and, within these Global Spaces Specific Zones of Intense Acummulation were created.

\section{KEY WORDS}

Global capitalism. Expansion. Accumulation. Transnational. Megaprojects. Infrastructure.

Recebido em: 03/07/2019

Aprovado em: 03/12/2019 